\title{
Reducing the carbon footprint of Whisky production through the use of a battery and heat storage alongside renewable generation
}

\author{
Wolf-Gerrit Früh ${ }^{1}$, Jamie Hillis ${ }^{2}$, Sandy Gataora ${ }^{3}$, Dawn Maskell ${ }^{4}$ \\ ${ }^{1}$ Institute of Mechanical, Process and Energy Engineering, School of Engineering \& Physical Sciences, Heriot-Watt \\ University, Riccarton, Edinburgh EH14 4AS, Scotland (UK), e-mail: w.g.fruh@hw.ac.uk \\ ${ }^{2}$ Sunamp Ltd., 1 Satellite Park, Macmerry, East Lothian, EH33 1RY, e-mail: Jamie.Hillis@sunamp.com \\ ${ }^{3}$ Sunamp Ltd., 1 Satellite Park, Macmerry, East Lothian, EH33 1RY, e-mail: sandy.gataora@sunamp.com \\ ${ }^{4}$ International Centre for Brewing \& Distilling, School of Engineering \& Physical Sciences, Heriot-Watt University, \\ Riccarton, Edinburgh, Scotland (UK), e-mail: D.L.Maskell@hw.ac.uk
}

\begin{abstract}
This paper presents an analysis of providing a typical distillery with low carbon energy through the combination of local wind energy, solar PV, electricity storage and heat storage. The aim of this is to increase the sustainability of the energyintensive whisky industry.

Using hourly local renewable resource data and typical distillery consumption information, the local energy generation is balanced against the demand at the time of use. This followed by load shifting using a battery and heat storage. Results show that significant carbon savings can be achieved by a carefully designed portfolio of hybrid generation, battery storage and heat storage.
\end{abstract}

Key words. Hybrid System, Wind Energy, Solar PV, Heat storage.

\section{Introduction}

The Whisky industry is one of the main industries in Scotland and is one of the energy intensive industries, where the heat demand for the production process alone requires typically $60 \mathrm{MJ}$ or $17 \mathrm{kWh}$ per litre alcohol (pLA). This is complemented by a similar amount of energy for the other parts of the distilleries' operation. With a typical annual output of a billion $\left(10^{9}\right)$ litres of whisky from around 130 distilleries in Scotland, this constituted around $20 \%$ of the UK's total food and drink export in 2019 [1]. With a typical alcohol content of $40 \% \mathrm{ABV}$ (alcohol by volume), this production equates to 400 million litres of alcohol or 6700 GWh of heat consumption or 13000 to $14000 \mathrm{GWh}$ of total energy consumption by the industry, which is about $10 \%$ of Scotland's total energy consumption [2]. Currently much of this heat demand is met by raising steam by electric heating or by burning fossil fuels but there is a drive to reduce the carbon footprint of the industry. For example, the UK Government has recently launched a 'Green Distilleries' competition [3] for Research and Development.
This paper evaluates the opportunities provided by combining local low-carbon electricity generation in the form of solar PV and/or wind energy with suitable heat and electricity storage to maximise the local exploitation of the low-carbon energy sources while being able to shift electric demand and heat load from times of high demand and low generation to times of availability of electricity. Even though this analysis is applied to a very specific application, the method and results are applicable for a wide range of energy-intensive industries.

While the size of the stills used by distilleries varies greatly, from around 2000 to 20000 litres, the standard batch process is common to the vast majority; after the initial heating of the 'wort' (germinated and ground barley in water) to $72^{\circ} \mathrm{C}$ to initiate fermentation, and the consequent fermentation to 'wash' with a typical alcohol concentration of about $8 \% \mathrm{ABV}$. The first distillation stage in the 'wash still' distils this wash, which has a boiling temperature of around $92^{\circ} \mathrm{C}$ and results in a 'low wine' with an alcohol content of about $20 \% \mathrm{ABV}$. The second distillation in the 'spirit still' then completes the distillation process (other varieties such as Irish whiskey uses three distillation stages).

Given the temperature requirements for the distillation, any thermal storage has to store and provide heat at temperatures above $100^{\circ} \mathrm{C}$. Technologies which could provide this are either steam accumulators [4] or phase change material (PCM) energy storage devices [5], also known as 'heat batteries'.

The aim of this paper is to explore how much low-carbon on-site generation and heat demand management can improve the environmental credentials of a distillery. This 
can be done in two ways; first, by using the on-site generation to contribute to the heat and electricity demand, either directly or via storage and secondly, by providing load shifting opportunities to the grid. This will enable renewable generation elsewhere to be accommodated on the grid.

In this paper, the energy consumption of a distillery operating the stills for a typical year will be modelled together with added PV and/or wind generation, a battery, and a phase change heat battery.

\section{Model development}

\section{A. Distillery}

The distillery modelled is scaled to a daily processing of 1000 litres of alcohol. For this, a wash still with an operating capacity of 12500 litres is required, and a day's heat consumption of $16.7 \mathrm{MWh}$ at a uniform rate of the operating time of the stills, assumed to be 6 hours from 10:00 to 16:00, giving a heat rate of $2.8 \mathrm{MW}$. At the same time, an electricity consumption for all other needs is assumed on a daily profile as given by Figure 1 . For the purpose of this analysis, it is assumed that the distillery operates 5 days a week for 49 weeks from the second Monday in the year, thereby simulating a closure over Christmas. At this stage, a uniform electricity consumption throughout the year is assumed. While this is a simplification, there will be higher heating and lighting demand in the winter for the working spaces but more demand for the visitor centre during the tourist season over the summer. This idealised profile leads to a minimum demand of $0.3 \mathrm{MW}$ and a peak of $3.6 \mathrm{MW}$ with a daily electricity consumption of $13 \mathrm{MWh}$ and a heat consumption during distillation of 19.6 MWh.

The availability and cost of grid electricity is represented by a time-varying tariff specified at hourly intervals. Assuming that both, the electricity and heat demand are provided through grid electricity without onsite generation and without storage, this tariff results in an annual electricity bill of $£ 7.3$ million.

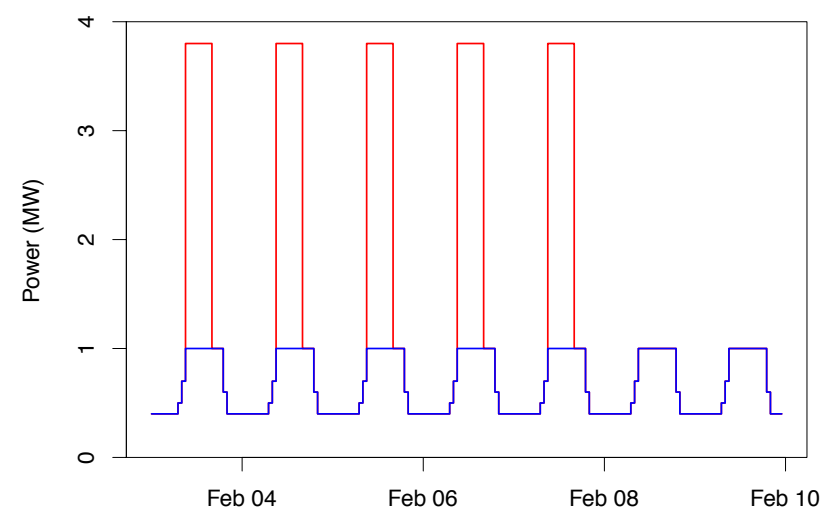

Fig.1. Weekly electricity load (in blue) and heat demand (red).

\section{B. Renewable energy resources and technologies}

The resource data are hourly irradiances and wind speeds at $10 \mathrm{~m}$ and $100 \mathrm{~m}$ above ground for a location in Scotland, provided by the Copernicus Climate Change Service [6] for one year (2020).

The direct and total surface shortwave radiation is converted to PV output for a fixed-tilt system with a tilt angle of $56^{\circ}$ facing due south, and the wind speeds are interpolated, using a power law wind shear factor to a hub height of $70 \mathrm{~m}$, representing a typical $1 \mathrm{MW}$ wind turbine, and then converted to wind power using a generic performance curve; cut-in wind speed $3 \mathrm{~m} / \mathrm{s}$, rated wind speed $12 \mathrm{~m} / \mathrm{s}$, and cut-out wind speed $25 \mathrm{~m} / \mathrm{s}$.

\section{Storage technologies}

The battery was specified with a variable capacity and a round-trip efficiency of $90 \%$. For the thermal storage, a phase change heat battery similar to specifications of a Sunamp UniQ device [7] with a round-trip efficiency of $95 \%$. At this stage, self-discharge and capacity degradation are not yet included in the models. However, since the degradation of phase change heat storage devices is much slower than that of batteries, the use of the heat storage device is prioritised over the battery. Conversely, locally generated electricity is used to serve the electricity load before contributing to the heat load.

\section{Model structure}

In the first step of the model, the local generation is used to offset the local demand. From this, the excess generation and the residual load are identified as illustrated in Figure 2 for an example of two $1 \mathrm{MW}$ wind turbines and $1 \mathrm{MW}$ of PV.

In the second step, the battery and heat battery complement the demand with the charge available from the previous day. After this, any surplus generation is used to recharge first the heat battery, then the battery, and finally export surplus to the grid using a net-metering approach. In the final step, the heat battery and battery are charged overnight making use of low night-time tariffs.

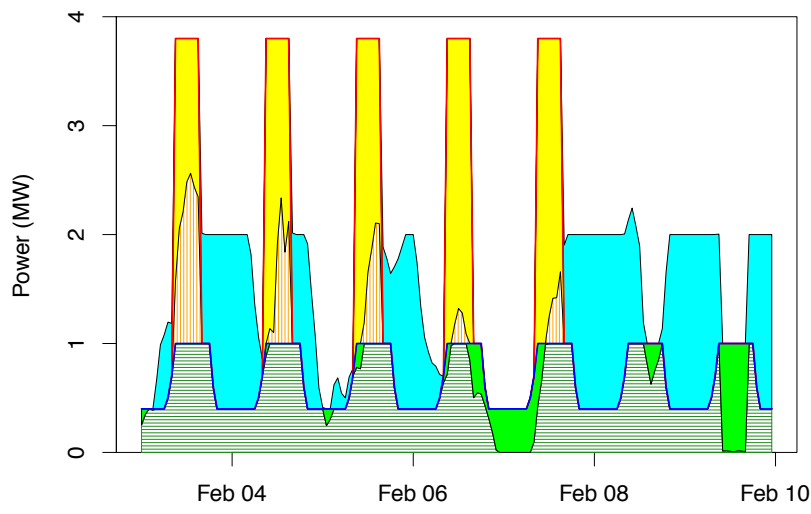

Fig.2. Contribution of local generation to demand (shaded areas), residual load (green area for electricity and yellow for heat), and excess generation (cyan area). 
The battery model operates on a method in which battery charge is reserved in the times leading up the time of need. This reserving is applied successively to times of need which have been arranged in a specified priority list. The algorithm to model the battery is given in Algorithm 1. For the purpose this analysis, the times of need were sorted in descending order of electricity tariff. This means that the most expensive electricity import is addressed first, followed by the $2^{\text {nd }}$-most expensive, etc.. This is first applied to the PCM heat battery. The resulting residual load and surplus is then used when the same algorithm is called again but configured to represent the (electricity) battery.

The performance of the system is measured against the annual amount of locally generation used within the distillery directly, generated locally but stored in the two storage technologies, and electricity imported from the grid. Secondary performance indicators are the electricity costs incurred over the year and income from exporting surplus to the grid.

\section{Results}

This section presents first the generation potential from both, wind energy and solar PV. The second subsection presents the effect on the local demand from a range of installed capacities but in the absence of any storage. The final two sections address the effect of additional storage on two renewable scenarios, one with a moderate wind and PV installation, and one with a substantial local generation.

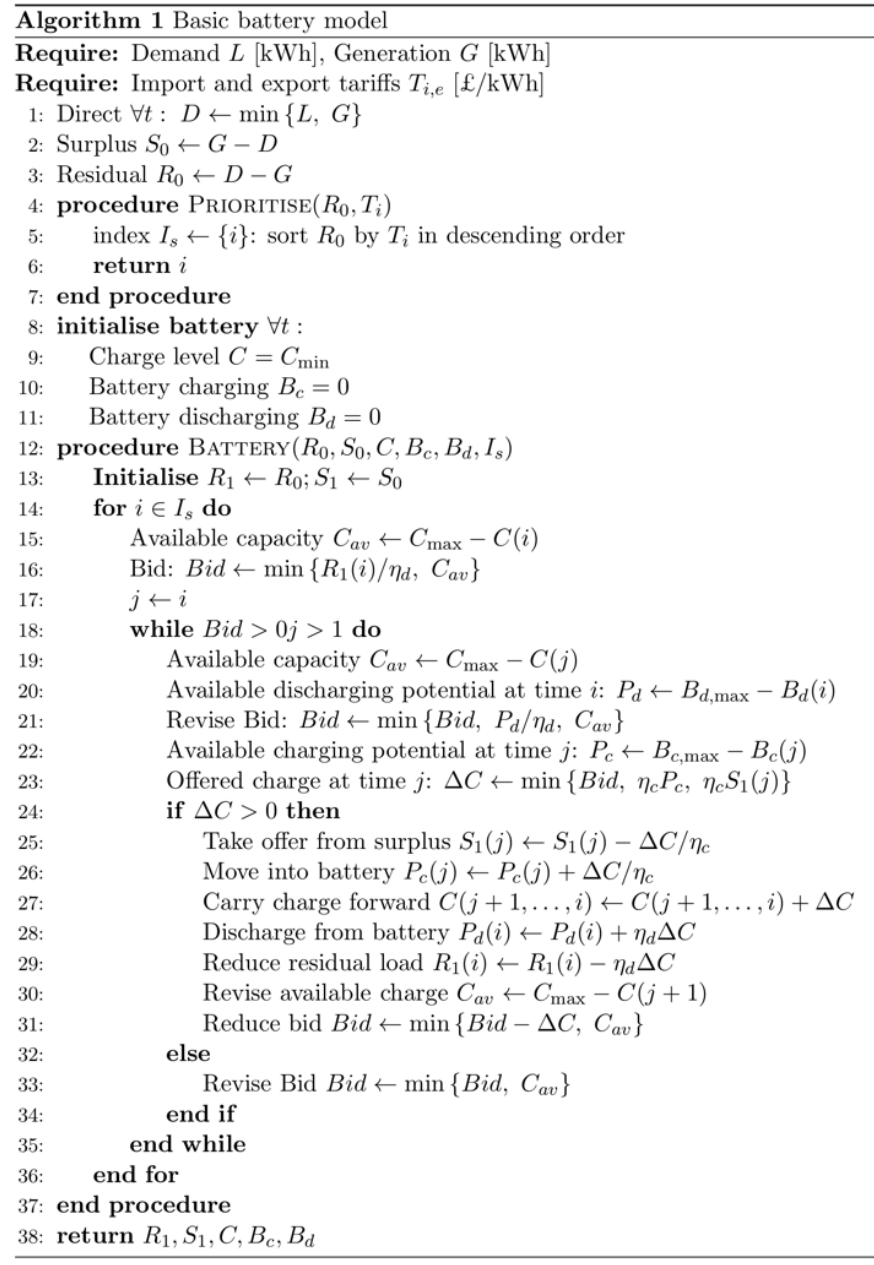

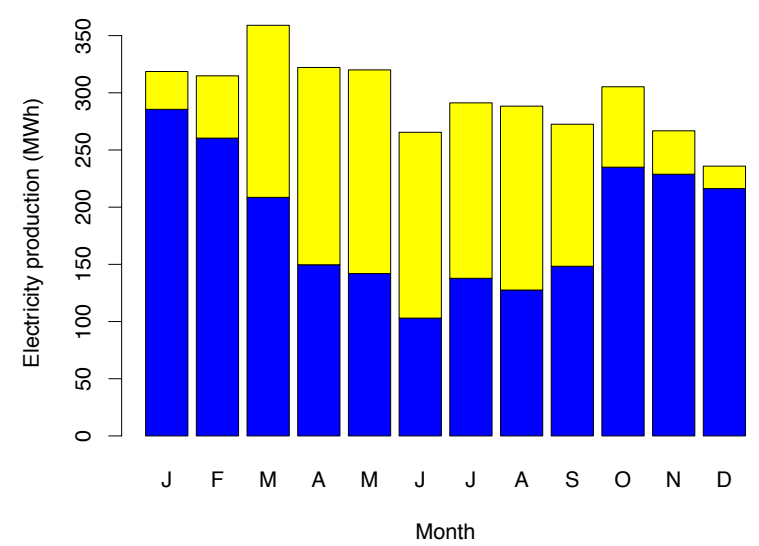

Fig.3. Output from $1 \mathrm{MW}$ wind (blue) and $1 \mathrm{MW}$ PV (yellow).

\section{A. Renewable Generation}

Figure 3 shows the electricity generation accumulated to a monthly production from a $1 \mathrm{MW}$ wind turbine and $1 \mathrm{MW}$ PV installation. This shows that the two resources complement each other well with more wind production in the winter and more PV production in the summer.

\section{B. Change of installed capacity with no storage}

Figure 4 shows the electricity directly used by the distillery at the time of generation for a range of installed capacities, each line showing it against the installed PV capacity for a fixed number of wind turbines.

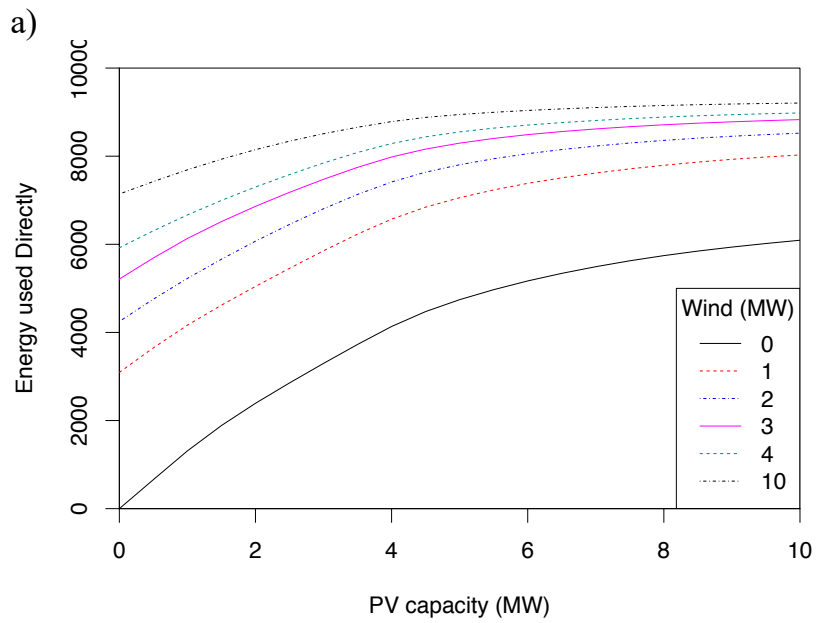

b)

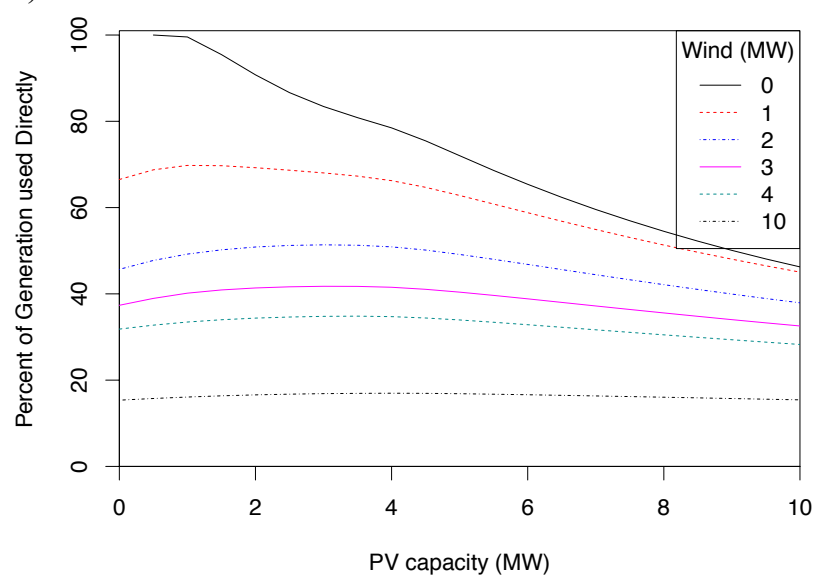

Fig.4. Part of the local generation is used directly; a) in kWh b) as a percentage of the local generation 


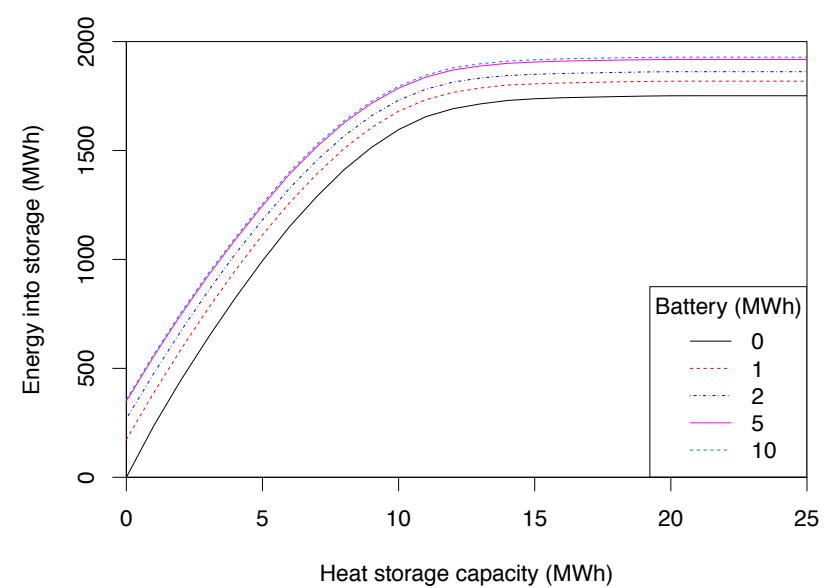

Fig.5. Renewable electricity utilised by storage against heat storage capacity for a selection of five battery capacities, for $2 \mathrm{MW}$ wind and $2 \mathrm{MW}$ PV.

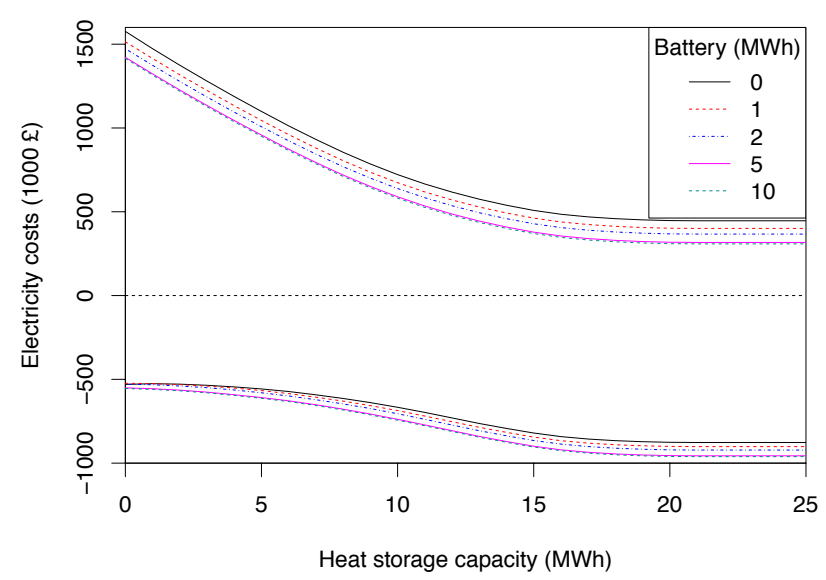

Fig.6. Annual electricity cost against heat storage capacity for a selection of five battery capacities, for $2 \mathrm{MW}$ wind and $2 \mathrm{MW}$ PV. Upper lines for gross import cost; lower lines for net cost (income) due to export.

Without any wind turbines, the electricity locally consumed increased initially rapidly to an installed capacity of around $5 \mathrm{MW}$ which is about $40 \%$ above the peak demand. Beyond this, the benefit from additional PV capacity levels off. A similar behaviour is seen for wind power only but the drop in the direct use occurs at around $3 \mathrm{MW}$, ie, at an installed wind capacity close to the peak demand.

\section{Change of storage capacity with moderate generation}

Based on the observations from Figure 4, this section presents the contribution for a range of storage capacity with $2 \mathrm{MW}$ of wind and $2 \mathrm{MW}$ of PV, that is in region where clear benefit from further renewable capacity without storage would be possible. In the following section, the analysis is repeated for $4 \mathrm{MW}$ wind and $4 \mathrm{MW}$ PV where the local generation can no longer be used to its best effect.

Figure 5 shows the amount of local generation which can be utilised locally in addition to the direct use shown in Fig. 4. Initially this increases rapidly up to a heat storage capacity of $10 \mathrm{MWh}$, which is about half of a day's heat consumption. Adding a battery for electricity storage increases the amount slightly up to a battery capacity of around 3 to $4 \mathrm{MWh}$, which is about a quarter of the daily electricity consumption.

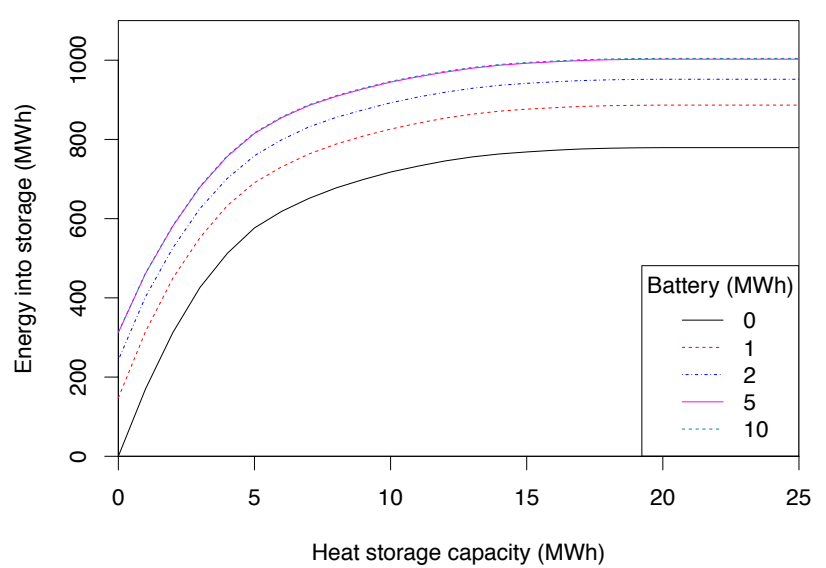

Fig.7. Renewable electricity utilised by storage against heat storage capacity for a selection of five battery capacities, for $4 \mathrm{MW}$ wind and $4 \mathrm{MW} \mathrm{PV}$.

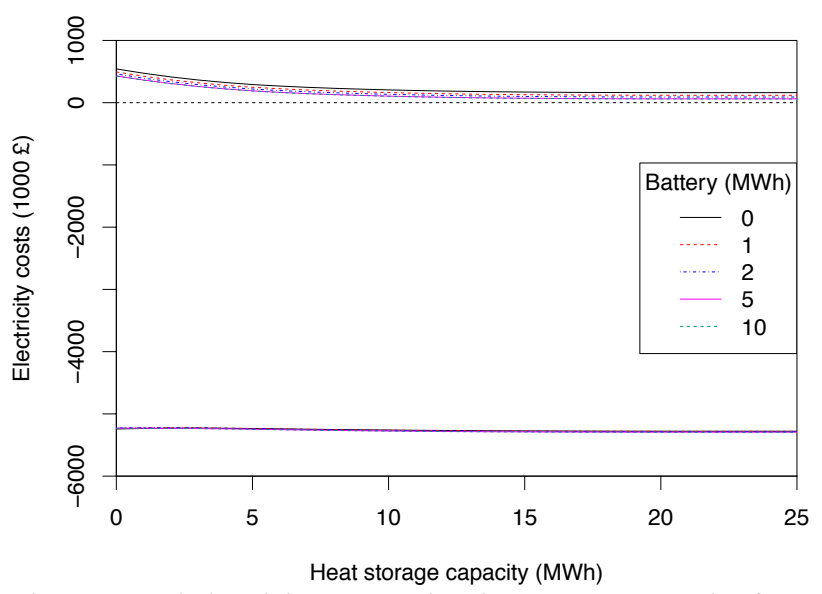

Fig.8. Annual electricity cost against heat storage capacity for a selection of five battery capacities, for $2 \mathrm{MW}$ wind and $2 \mathrm{MW}$ PV. Upper lines for gross import cost; lower lines for net cost (income) due to export.

In relative terms, the most additional use through storage is $15 \%$ of the annual electricity production.

Converting this to cost savings from both reduction in imports due to the onsite generation and load shifting through the remaining storage capacity is shown in Figure 6. In addition, the lower set of lines shows the net costs if surplus generation can be exported to the grid without any constraints. Without storage, the bill for electricity import is already reduced from $£ 7.3$ million to $£ 1.5$ million, and storage reduces this to $£ 500 \mathrm{k}$. Including revenue from exporting surplus generation increases the net income from $£ 500 \mathrm{k}$ to $£ 1 \mathrm{~m}$.

\section{Change of storage capacity with substantial generation}

The results for the more substantial installation of $4 \mathrm{MW}$ wind and $4 \mathrm{MW} \mathrm{PV}$ is summarised here.

Figure 7 shows the amount local generation which can be utilised locally in addition to that used directly. The shape is similar to that in Figure 5 but the additional benefit levels off earlier and at a much lower level, only half of what was utilised with moderate generation. In relative terms, the most additional use through storage is around $5 \%$ of the annual electricity production. 
a)

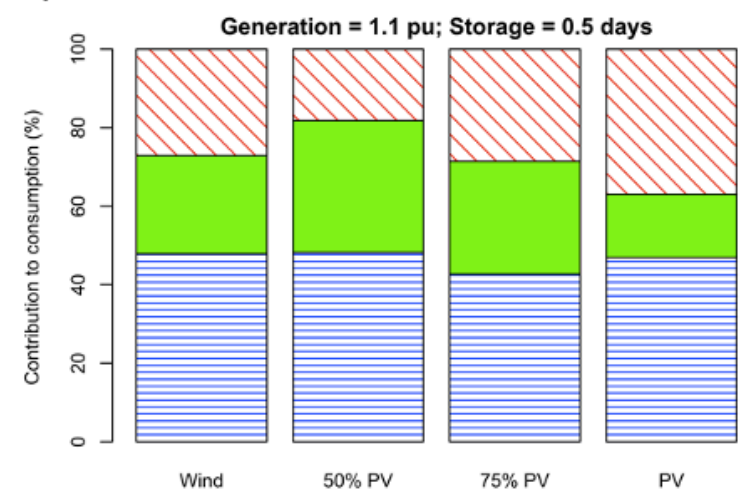

c)

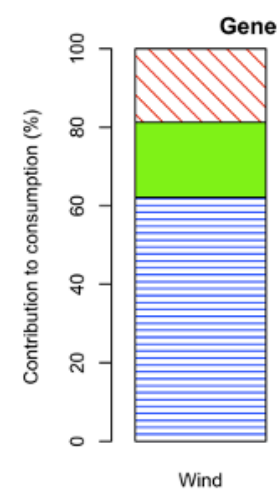

b)

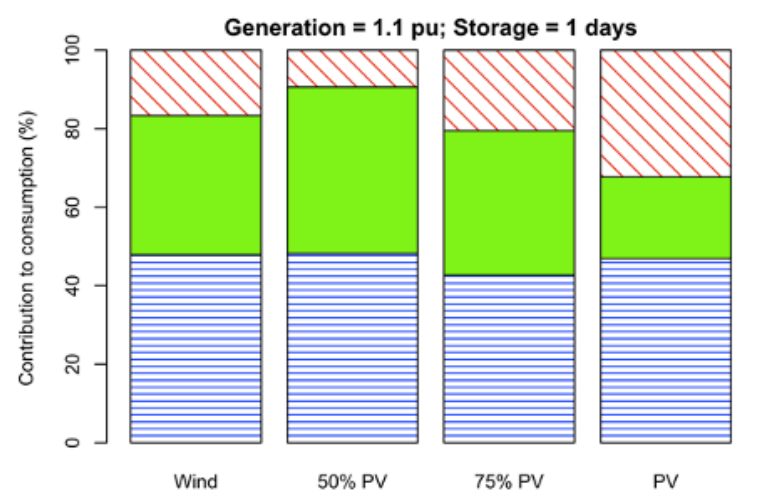

d)

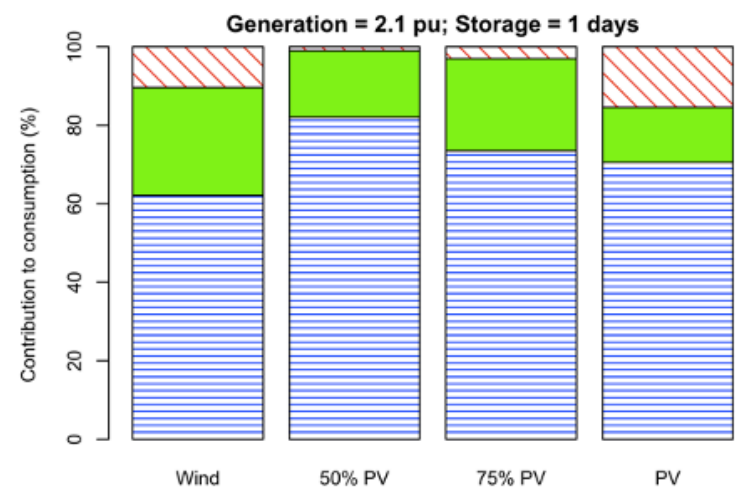

Figure 9. Split between local generation used directly for heat load (blue lines), local generation used via storage (green area), and residual load (red diagonals). Top row for unit generation capacity, bottom row for doubled capacity. Left column for storage size to meet half of working day's worth of operation, right column for storage size to meet a full working day's consumption.

The annual costs or income of this system would be completely dominated by income from excess electricity resulting in a net income of $£ 5 \mathrm{~m}$ compared to the initial cost of $£ 7.4 \mathrm{~m}$. In this case, the distillery would become a major electricity generator. In more realistic cases, especially considering that many distilleries in Scotland are located in areas where the grid is relatively weak, it might be more useful to look at the residual electricity import required despite the massive overproduction.

Figure 8 shows that additional storage can significantly reduce electricity imports. Heat storage alone will only be sufficient to serve heat requirements but a combination of can effectively reduce the overall need for importing energy. However, even this cannot remove the need for additional energy from the grid altogether, but a heat storage capacity of about $15 \mathrm{MWh}$ combined with a battery of 4 MWh achieves the maximum reduction.

From an initial total annual consumption of $9500 \mathrm{MWh}$, the renewable generation provides about $8300 \mathrm{MWh}$, while the storage can provide a final $900 \mathrm{MWh}$, still leaving a final $420 \mathrm{MWh}$ to be found from the grid.

\section{Portfolio optimisation}

So far, the analysis has presented the results for a particular situation. In this section, we try to place the respective benefits of local low-carbon generation and storage into a wider context of a regular and consistent heat demand at reference level $1 \mathrm{pu}$ for the duration of a typical working day. The results so far suggest that local generation capacity of a magnitude similar to the heat load, or slightly higher, will present significant benefits. Furthermore, there are clear additional benefits for a moderately sized storage element with an energy capacity of between a half day's and a full day's operation. At higher generation capacity, the amount of locally generated and used electricity levels off, always leaving a residual demand while simply increasing surplus generation. Depending on the local context, this surplus, or part of it, can be sold to the grid, or it has to be curtailed. Adding storage helps to reduce the residual storage by balancing generation and demand over a fairly short time span of a few days only, while complete local utilisation of local generation across season would require an unrealistically large storage capacity.

The split between a) the directly utilised local low-carbon electricity, b) that utilised by the storage, and c) the remaining need for supplementary electricity is clearly illustrated for a selection of 'intermediate'-sized 
installations in Figure 9. The top row shows two battery sizes for an installed capacity about equal to the nominal heat load, where the first bar is for a generation portfolio using only wind turbines, the $2^{\text {nd }}$ bar has a mix of $0.5 \mathrm{pu}$ installed wind capacity and $0.5 \mathrm{pu}$ Solar PV. The third column has $0.25 \mathrm{pu}$ wind and $0.75 \mathrm{pu}$ PV where the annual wind production is about the same as the annual PV production, and the final column is for solar PV only. Figure 9a is for a storage size to store half a day's of operation, while Figure $9 \mathrm{~b}$ is for a full day's operation. At low generation capacity, only just exceeding the nominal load, around $50 \%$ of the local generation can be used directly. Adding storage increases the utilisation of the generation significantly, with a clear increased contribution from 0.5 days to a full day's consumption. The smallest benefit is when storage is coupled to solar PV only. This can be explained by the very large seasonal variation between winter and summer. Even though wind energy also has a seasonal variation, this is much smaller compared to the variability across a day or a week. As a result, storage can facilitate the operation more easily. Most substantial benefits are by coupling storage to hybrid installations, where the two seasonal variations, more sun in the summer and more wind in the autumn and winter, complement each other.

The second row in Figure 9 shows the same information for the same battery choices but doubled renewable generation. Here, the directly used generation is much higher, leaving less opportunity for benefits from the battery. This also results in much smaller increase of the storage utilisation of the larger battery. While the hybrid installations in Figure $9 \mathrm{~d}$ use the battery less than the wind-only installation, they achieve almost self-sufficiency, with only a few percent of the heat load to be supplied from other sources, such as grid electricity or a back-up generator.

This analysis clearly shows that the best choice of renewable generation and energy storage is a tightly interconnected problem, depending strongly on the nature of the local resource and the purpose of the installation, whether it is to maximise cost savings or self-sufficiency.

\section{Conclusion and Further Work}

This analysis demonstrates that the combined use of onsite generation and local storage is beneficial for an energy intensive industrial site. However, it has become clear that the size of the local demand, installed generation capacity and storage capacity need to be carefully matched to realise that potential. If the generation is small compared to the onsite demand, then it provides a small reduction in load while any storage device will only be occasionally used. If, however the generation is very large, then the local benefit is dwarfed by the excess electricity generation which would need to be exported. This obviously relies on a strong grid connection and a contract which allows substantial exports. In this case, the local site would become a major generator alongside its original purpose. In this case, any storage device will be less useful to serve local needs, though it might become essential to balance the grid. This latter option, however, was not evaluated in detail here, where the primary purpose was to serve local consumption while allowing some surplus to be exported.

In the intermediate range, where the local generation capacity is aligned with the demand, storage can indeed provide an effective benefit as long as it is large enough to manage a sizable fraction of a day's consumption. No benefit was observed for storage capacities exceeding a day's production. This might partly be due to the particular location of the system, based on an island off the west coast of Scotland with an excellent wind resource and even a good solar resource during the summer months, when the wind tends to be at its lowest.

Further work will need to go into more detail of finding guidelines for optimum sizing, not only in terms of electricity production but also setting of installation costs. Other further work will need to analyse the sensitivity of the results to interannual variability - at this stage, only one typical year's worth of resource data was used, and also to apply this methodology to other locations with different wind and solar climates.

\section{Acknowledgement}

The authors are grateful to the UK Department of Business, Enterprise and Industrial Strategy for funding through the Green Distilleries competition [3].

\section{References}

[1] The Scottish Whisky Association, https://www.scotchwhisky.org.uk/.

[2] Scottish Government, Scottish Energy Hub, (ND, accessed 17 March 2021), https://scotland.shinyapps.io/Energy/.

[3] UK Department for Business, Energy and Industrial Strategy, Green distilleries competition, (2020), https://www.gov.uk/government/publications/greendistilleries-competition.

[4] W. Sun, Y. Hong, Y. Wang, "Operation Optimization of Steam Accumulators as Thermal Energy Storage and Buffer Units", Energies (2017). Vol. 10, 17, https://doi.org/10.3390/en10010017

[5] MM Farid, AM Khudhair, SAK Razack, S Al-Hallaj, "A review on phase change energy storage: materials and applications", Energy Conversion and Management (2004). Vol. 45, pp. 1597-1615, DOI:10.1016/j.enconman.2003.09.015.

[6] H. Hersbach, B. Bell, P. Berrisford, G. Biavati, A. Horányi, J. Muñoz Sabater, J. Nicolas, C. Peubey, R. Radu, I. Rozum, D. Schepers, A. Simmons, C. Soci, D. Dee, J-N. Thépaut, ERA5 hourly data on pressure levels from 1979 to present, (2018). Copernicus Climate Change Service (C3S) Climate Data Store (CDS). (Accessed on 10 Mar-2021), DOI:10.24381/cds.bd0915c6

[7] Sunamp Ltd., https://sunamp.com/. 